\title{
LA INMIGRACIÓN VENEZOLANA EN EL PERÚ VISTA DESDE UNA PERSPECTIVA DE SALUD
}

\author{
VENEZUELAN IMMIGRATION IN PERU FROM A HEALTH PERSPECTIVE
}

\author{
Walter Mendoza $1, a$
}

La visibilidad e implicancias de los procesos demográficos son crecientes en la agenda de investigación y en el diseño de políticas públicas. A los rezagos de problemas en la salud materno-infantil, en los últimos años se ha sumado el envejecimiento, y más recientemente la migración, tanto la de salida como de retorno, y que ha generado múltiples investigaciones, inesperados desafíos, pero también oportunidades. La relación entre migración y salud ha sido tema de interés de la Revista Peruana de Medicina Experimental y Salud Pública (RPMESP) habiéndole dedicado algunos de sus artículos en números pasados ${ }^{(1)}$.

En Perú, una de las mayores e inesperadas novedades demográficas ha sido convertirnos en país de destino migratorio, con la llegada de cientos de miles de venezolanos y venezolanas. Junto a Colombia, Ecuador y Chile compartimos una situación inédita y desafiante para nuestra solidaridad, lo que supone acondicionar nuestros servicios sociales, salud, educación y empleo. Son países con los que, afrontando situaciones similares, debemos compartir no sólo investigación en el tema de migración, sino también respuestas coordinadas desde un enfoque de derechos.

La RPMESP dedica su tercer número al fenómeno de migración de llegada, con contribuciones que van desde la evaluación de la calidad de vida en relación a la salud, a su situación de salud general, así como la situación nutricional de niños en el punto de ingreso norte en Tumbes. El número también incluye una revisión sistemática, a cargo de Larenas-Rosa et al (2), que identifica iniciativas dirigidas al acceso a servicios de salud de población migrante internacional en situación irregular. Los autores resaltan su alta vulnerabilidad, así como la escasez de estudios realizados en Sudamérica. También que las iniciativas identificadas carecen de interés en la salud sexual y reproductiva, así como de perspectiva de género y competencia cultural.

El estudio de Figueroa-Quiñonez et al. ${ }^{(3)}$ sobre la calidad de vida relacionada con la salud, reporta altos niveles de ansiedad y depresión (en dos tercios de participantes), especialmente en quienes tenían instrucción universitaria. Por su parte Mendoza et al. (4) describen las condiciones de salud reportadas por migrantes venezolanos/as, en su mayoría jóvenes, a partir de la encuesta que aplicó el Instituto Nacional de Estadística e Informática (INEI) a fines del 2018. El análisis destaca el limitado acceso a servicios en salud sexual y reproductiva. Asimismo, encuentra que entre los migrantes hay algunos miles con estudios técnicos o avanzados en profesiones de la salud, incluyendo titulados, situación que ameritaría mayor atención por parte de las autoridades sanitarias.

Las condiciones nutricionales de niños menores de cinco años en el punto de entrada en Tumbes son estudiadas por Vargas-Machuca et al. ${ }^{(5)}$ mediante mediciones realizadas en dos momentos (agosto 2018 y marzo 2019), evaluaron la antropometría, se descartó anemia y se aplicó una entrevista de salud y alimentación reciente. La desnutrición crónica, en torno al 18\%, fue encontrada en niveles superiores al promedio de niños peruanos de la misma edad (12\%); no así la anemia (35 y 25\% en cada medición), que en nuestro país supera el $40 \%$.

Por otro lado, la sección de artículos originales trae un par de trabajos de gran interés para hacer frente a dos desafíos sanitarios: el de Tarqui-Terrones et al. ${ }^{(6)}$ que aplica una metodología reproducible para extraer ADN de Giardia spp. Según sus resultados se pueden realizar estudios de caracterización y resistencia molecular de la forma invasiva e infectante del parásito, causante de anemia y desnutrición crónica ${ }^{(7)}$. A su vez,

Fondo de Población de las Naciones Unidas (UNFPA). Lima, Perú.

Médico cirujano

Recibido: 10/09/2019 Aprobado: 18/09/2019 En línea: 23/09/2019

Citar como: Mendoza W. La inmigración venezolana en el Perú vista desde una perspectiva de salud. Rev Peru Med Exp Salud Publica. 2019;36(3):381-2.doi: http://dx.doi. org/10.17843/rpmesp.2019.363.4812 
Sinti-Hesse et al. ${ }^{(8)}$ estudian el rol de las embarcaciones fluviales como medio de dispersión de Aedes aegypti, vector del dengue, chikungunya y zika. Encuentran un moderado a alto riesgo entomológico durante la época de creciente en embarcaciones fluviales que viajan desde Iquitos hacia las zonas fronterizas de Loreto.

La sección de originales breves está cubierta por una amplia variedad temática, desde la neonatología con un estudio de casos de hemorragia intraventricular en recién nacidos con menos de <2000 gramos en tres hospitales de Lima, en los que se encuentran similar frecuencia que en otros países, aunque mayor severidad y mortalidad; hasta la detección molecular de enfermedades genéticas poco frecuentes en nuestro medio. También en esta sección se presenta un estudio sobre la salmonelosis invasiva en un hospital de Lima, más frecuente en niños pequeños y ancianos; además la infección por VIH fue la comorbilidad más frecuente. Asimismo, se hacen recomendaciones terapéuticas, a partir del análisis de su perfil de susceptibilidad.

Finalmente, otras secciones del número incluyen reportes de casos e historia de la salud pública. En esta última, encontramos el interesante artículo de Romani F. (9) dedicado a uno de los fundadores de la RPMESP, en el que se da cuenta de su historia y clima cultural durante la primera mitad del siglo XX. En él se explica la inclusión y persistencia de la Medicina Experimental en su nombre, a pesar que esta revista publica en su mayoría estudios observacionales. En momentos en que la medicina vive tensiones de paradigma en un entorno de acelerada innovación tecnológica, artículos como este incentivan una discusión urgente en nuestro país, en tanto persisten condiciones de dependencia teórica respecto de los centros de poder científico en el mundo.

\section{REFERENCIAS BIBLIOGRÁFICAS}

1 Cabieses B, Gálvez P, Ajraz N. Migración internacional y salud: el aporte de las teorías sociales migratorias a las decisiones en salud pública. Rev Peru Med Exp Salud Publica. 2018;35(2):285-91. doi: 10.17843/rpmesp.2018.352.3102.

2 Larenas-Rosa D, Cabieses Valdés B. Salud de migrantes internacionales en situación irregular: una revisión narrativa de iniciativas. RevPeruMedExpSalud Publica. 2019;36(3):487-96. doi:http://dx.doi. org/10.17843/rpmesp.2019.363.4469

3 Figueroa-Quiñonez J, Ipanaqué-Neyra J, Ipanaqué-Zapata M, Taype-Rondan A. Calidad de vida en migrantes venezolanos que radican en las ciudades de Chimbote y Nuevo Chimbote, Perú. Rev Peru Med Exp Salud Publica. 2019;36(3):383-91.

4 Mendoza W, Miranda JJ. La inmigración venezolana en el Perú: desafíos y oportunidades desde la perspectiva de la salud. Rev Peru Med Exp Salud Publica. 2019;36(3):497-503.

5 Vargas-Machuca R, Rojas-Dávila CE, Jiménez MM, Piscoya C, Rázuri H, Ugaz ME. La situación nutricional de los niños migrantes venezolanos menores de 5 años al momento de su ingreso al Perú y las acciones emprendidas para proteger su salud y nutrición. Rev Peru Med Exp Salud Publica. 2019;36(3):504-10.

6 Tarqui-Terrones K, Silva-Molina JI, Beltrán-Fabián M, Zevallos-Vara S, MaytaHuatuco E. Comparación de métodos de extracción de ADN de Giardia spp. medidos por PCR convencional. Rev Peru Med Exp Salud Publica. 2019;36(3):42332. doi:http://dx.doi.org/10.17843/ rpmesp.2019.363.4160.

7 Cabada MM, Goodrich MR, Graham B, Villanueva-Meyer PG, Deichsel EL,
Lopez M, et al. Prevalence of intestinal helminths, anemia, and malnutrition in Paucartambo, Peru. Rev Panam Salud Publica. 2015;37(2):69-75.

8 Sinti-Hesse C, Díaz-Soria F, CasanovaRojas W, Carey-Angeles C, Tello-Espinoza $\mathrm{R}$, Espinoza J, et al. Embarcaciones fluviales como medio de dispersión de Aedes aegypti hacia zonas fronterizas de la Amazonía peruana. Rev Peru Med Exp Salud Publica. 2019;36(3):392-9. doi: http://dx.doi. org/10.17843/rpmesp.2019.363.4558.

9 Romaní F. De Claude Bernard a Telémaco Battistini: la medicina experimental en el nacimiento de la revista científica del Instituto Nacional de Salud del Perú. Rev Peru Med Exp Salud Publica. 2019;36(3):530-4. doi:http://dx.doi. org/10.17843/rpmesp.2019.363.4512. 